\title{
Slant perception in near space is categorically biased: Evidence for a vertical tendency
}

\author{
FranK H. DURGIN AND ZHI LI \\ Swarthmore College, Swarthmore, Pennsylvania \\ AND \\ Alen Hajnal \\ University of Southern Mississippi, Hattiesburg, Mississippi
}

\begin{abstract}
The geographical slants of hills are known to appear quite exaggerated. Here, we examine the visual and haptic perception of the geographical slant of surfaces within reach under full-cue conditions and show that the perceived orientation of even these surfaces is biased. An exaggeration with respect to deviations from horizontal is shown to be present cross-modally. Experiment 1 employed numerical estimation to show the effect for visually observed surfaces, while controlling for verbal numerical bias. Experiment 2 demonstrated that the bias is present even when manual measures show good calibration. Experiment 3 controlled for direction of gaze. Experiment 4 measured the same bias for haptic surfaces. Experiment 5 showed that the bias can also be observed using the nonnumeric task of angle bisection. These results constrain theories of geographical slant perception and appear most consistent with functional scale expansion of deviations from horizontal.
\end{abstract}

Gibson (1950) proposed that surfaces, rather than spaces, were the objects of perception. Here, we show that the perceived geographical slants of surfaces in near space are systematically biased. Geographical slant refers to the slant of a surface relative to the horizontal plane (Sedgwick, 1986). Perceived geographical slant is known to be exaggerated for large distal surfaces, such as hills (Kammann, 1967; Proffitt, Bhalla, Gossweiler, \& Midgett, 1995; Ross, 1974). We have recently found that ramps feel very steep under foot (Hajnal, Abdul-Malak, \& Durgin, in press). Our present investigation shows that the perceived slants of small surfaces within reach of the hand are also exaggerated. We will argue that these biases cannot be explained by the frontal tendency observed by Gibson (1950; see also Ooi, Wu, \& He, 2006) but seem to be due to systematic spatial coding distortions, relative to the categorical references of horizontal and vertical.

Many investigators have considered how various visual factors and sources of information, relevant to depth and shape perception, may affect the perception of slant (M. S. Banks, Hooge, \& Backus, 2001; Bridgeman \& Hoover, 2008; Clark, Smith, \& Rabe, 1956; Flock, 1965; Gibson, 1950; Gibson \& Cornsweet, 1952; Gruber \& Clark, 1956; Howard \& Kaneko, 1994; Kaneko \& Howard, 1997; Knill, 1998; Knill \& Saunders, 2003; Li \& Durgin, 2009; Norman, Crabtree, Bartholomew, \& Ferrell, 2009; O'Shea \& Ross, 2007; Perrone, 1982). Our concern is not with the specific sources of visual (or nonvisual) information, but with perceptual experience as reported by our par- ticipants. Our (real) surfaces are presented under full-cue conditions, in the absence of any cue conflict.

Gibson and Cornsweet (1952) defined optical slant as the orientation of a surface relative to the axis of gaze (i.e., relative to the set of planes to which the line of sight forms a normal vector). Using a vertical palm board measure, Gibson (1950) observed evidence of a frontal tendency in estimates of slant from texture gradients. That is, his texture-gradient-defined surfaces appeared more frontal to gaze than they were. Consistent with modern views, Gibson noted that such effects might be partly caused by conflicting cues to flatness (such as the lack of accommodative blur in his monocular stimuli) and partly by the aperture through which his participants looked at the stimuli, a factor that has also later been confirmed (Eby \& Braunstein, 1995). Although it was only later that Gibson and Cornsweet explicitly distinguished optical slant from geographical slant experimentally, the frontal tendency has been assumed to reference optical slant or egocentric slant: In the absence of depth information indicating otherwise (e.g., from contour, surface texture, binocular disparity, etc.), a surface in the visual field appears frontal to gaze.

In Gibson's (1950) early framework, a frontal surface was defined as having zero optical slant, so that the frontal tendency was described as the underestimation of slant (see also Norman et al., 2009). Here, we follow, instead, Sedgwick's (1986) practice of defining optical slant so that a frontal surface is stipulated as having an optical

F. H. Durgin, fdurgin1@swarthmore.edu 
slant of $90^{\circ}$ (see also Li \& Durgin, 2009). This formalization is more compatible with the scaling of geographical slant, such that when gaze is forward, for example, optical slant and geographical slant are rendered equivalent. Thus, in the present formalization, frontal tendency may be specified as the overestimation of optical slants that are less than $90^{\circ}$ (and the underestimation of optical slants that are greater than $90^{\circ}$ ). In fact, our data will show that there are large biases in the perceived geographical slants of near surfaces that are not explained by frontal tendency but seem to resemble a vertical tendency.

We have recently shown that gesturing with an unseen hand can produce a good orientation match to near surfaces but that the use of palm boards (a board mounted on an axis that can be rotated by hand to represent an angle), such as have often been used for slant and hill perception in recent decades, produces underestimation of the geographical slant of surfaces within reach (Durgin, Hajnal, Li, Tonge, \& Stigliani, 2010). That is, when asked to rotate a board by hand to make it parallel with near surfaces in the range of $0^{\circ}-48^{\circ}$, participants set the board too low by a factor of about 0.6. Durgin et al. (2010) provided evidence that such palm board errors occurred because proprioception of wrist flexion is not calibrated. Haptic misperception of palm board orientation has led to the mistaken impression that palm boards are accurate measures of hill orientation (e.g., Creem \& Proffitt, 1998; Proffitt et al., 1995). Kaneko and Howard (1997) used palm board matches to full-cue surfaces to try to calibrate these measures for their main experiment but did not report the obtained functions. However, palm board data from Norman et al. (2009), for example, showed the same sort of measurement bias (toward horizontal) as that investigated by Durgin et al. (2010).

Durgin et al. (2010) did find that gesturing freely with an unseen hand produced a gain of essentially 1 for near full-cue surfaces but that similar gestures overestimated the slants of hills (see also Bridgeman \& Hoover, 2008). Durgin et al. (2010) argued that hand orientation is calibrated for near surfaces (with which the hand might reasonably interact): During reaches to a slanted surface in near space, the hand orients quite accurately before making contact. Devices like palm boards can apparently undermine the calibration present in the arm-hand assembly by requiring that hand and board orientation be controlled primarily by the wrist joint, which results in significant proprioceptive (and haptic) bias.

Whereas accurate gesturing suggests that unconstrained manual actions are calibrated for near surfaces, accurate action does not mean that perceptual experience is veridical. As has been demonstrated by prism adaptation (Harris, 1980; Redding \& Wallace, 1988), manual actions (including gesturing) can become calibrated (i.e., accurate and effective) even when visual experience is distorted (Durgin, 2009). Harris (1963) showed, for example, that one hand could become calibrated to act appropriately with respect to a prism-induced shift of visual space without the other hand being so. Similarly, locomotor adaptation to altered optic flow while hopping affects only the calibration of the hopped-on leg (Durgin, Fox, \& Kim, 2003). Thus, the accurate gesturing observed by Durgin et al. (2010) does not settle the question of whether the slants of surfaces viewed under full-cue conditions in near space are accurately perceived. If there were a systematic bias in the perception of surface orientation, manual actions that have become calibrated to that bias would be uninformative about it. We therefore sought to assess the perceptual experience of near surface slant under full-cue conditions in a more direct way.

As an alternative to manual gestures, one possibility is to use visual matching. For example, Li and Durgin (2009) used an adjustable oriented line as a nonverbal measure of perceived orientation (see also Todd, Guckes, \& Egan, 2009). However, there is reason to believe that the perception of 2-D orientation is itself biased (Dick \& Hochstein, 1989; Fisher, 1968; Howe \& Purves, 2004). Dick and Hochstein had people verbally categorize 2-D oriented lines using either vertical as zero or horizontal as zero. Under both codings, orientations near $30^{\circ}$ from horizontal were judged to be farther from horizontal (and closer to vertical). Dick and Hochstein showed that the form of the perceptual bias found was not predicted by the vertical/ horizontal illusion.

Verbal numeric reports of orientation may be the most straightforward way to obtain estimates of perceived slant. Whereas numeric scaling of perceptual magnitudes often produces a power function, there is reason to expect numeric scaling to be linear when confined to a limited range, such as $0^{\circ}-90^{\circ}$ (W. P. Banks \& Coleman, 1981). Whereas it might be argued that verbal numeric reports of orientation are intrinsically biased, we sought to separate verbal/numeric bias from spatial bias by asking some participants to make their verbal numeric estimates relative to horizontal and others to make them relative to vertical. In a later experiment we adopted a nonnumeric measure (angle bisection), which will provide converging evidence for the conclusion we draw from the numeric measures. Overall, our studies will show that there is a tendency in both visual and haptic perception for surfaces to seem farther from horizontal (and therefore, closer to vertical) than they are.

\section{EXPERIMENT 1 Numeric Estimates of the Slants of Visual Surfaces Within Reach}

To determine whether the perception of surface orientation in near space under full-cue conditions is biased, we collected verbal numeric estimates of slants, asking one set of participants to make their judgments relative to vertical and one set to make their judgments relative to horizontal. In order to be able to present the entire range of geographical slants from $0^{\circ}$ to $90^{\circ}$, and to control for bias produced by frontal tendency, wooden surfaces were presented in near space below chest level so that the direction of gaze was down by about $37^{\circ}$ onto the surfaces, meaning that geographical slants of $0^{\circ}-90^{\circ}$ corresponded to optical slants of about $37^{\circ}-127^{\circ}$. 


\section{Method}

A local ethics board approved all the procedures used in this report.

Participants. Twenty-seven Swarthmore College students (14 of them female; in this and all the following experiments, there were approximately equal numbers of male and female students) participated to fulfill a course requirement. They were naïve as to the hypotheses and were not told the experimental design.

Design. Sixteen geographical slants from $0^{\circ}$ to $90^{\circ}$ (by $6^{\circ}$ increments) were presented in random order, and an estimate was collected from each participant for each angle. To control for verbal bias, we asked 12 of the students to estimate surface orientation relative to horizontal $\left(0^{\circ}\right.$ to $\left.90^{\circ}\right)$, and 15 relative to vertical $\left(90^{\circ}\right.$ to $\left.0^{\circ}\right)$.

Apparatus. The apparatus was the same as that used by Durgin et al. (2010). Photographs of the setup are shown in Figure 1. Note that an observer would stand directly in front of the board (within reach of it). A metal slope-presentation device allowed a mounting surface to be quickly and accurately set by hand to any one of a number of preselected angles. A different, irregularly shaped wooden surface could be placed securely onto the mounting surface for each trial. The 18 wooden surfaces available were about $40 \mathrm{~cm}$ across, with an irregular perimeter. The surfaces were presented with the center $112 \mathrm{~cm}$ from the ground and about $60 \mathrm{~cm}$ in front of the participants, so that the direction of gaze to the center of the surface was typically declined $32^{\circ}-42^{\circ}$ from straight ahead (i.e., for eye heights of $150-166 \mathrm{~cm})$. The boards were lit from the sides to minimize specular reflections.

A hemispheric enclosure of black felt (about $2 \mathrm{~m}$ in diameter) served as the visual background. The surrounding room was visible only in the far periphery.

Procedure. The participants stood in front of the apparatus with their eyes closed between trials. The target surface was oriented and measured by the experimenter, and then the participant was allowed to view it binocularly without making large head motions. Once an estimate in degrees was provided, the experimenter selected a new wooden surface and prepared it for the next trial. The entire procedure took about $10 \mathrm{~min}$.

\section{Results and Discussion}

Figure 2 shows mean verbal reports for the two conditions expressed in two ways. In the left plot, orientations and responses are plotted in their nominal orientation, to check for verbal bias. In the right plot, all surfaces and verbal estimates have been arithmetically converted to refer to horizontal. Under both instructions, horizontal and vertical orientations were accurately reported, but intermediate slants showed a consistent spatial bias. Verbal reports relative to vertical tended to underestimate deviations from vertical, whereas those given relative to the horizontal tended to overestimate deviations from the horizontal. In the spatial plot (Figure 2, right), the two sets of estimates diverge reliably only for orientations of $18^{\circ}-24^{\circ}$ from horizontal. Because these two distinct verbal patterns otherwise represent the same underlying spatial bias, they seem to reflect the perceptual experience of our participants, rather than merely a numerical verbal bias. Figure 3 shows the mean signed errors, relative to horizontal, for all participants. It appears that whereas surfaces within $15^{\circ}$ of horizontal may be drawn toward horizontal, all other slanted surface orientations (from $24^{\circ}$ to $84^{\circ}$ of geographical slant) appear more vertical than they should.

Note that the pattern of distortion we are describing is clearly not due to a frontal tendency (which should predict

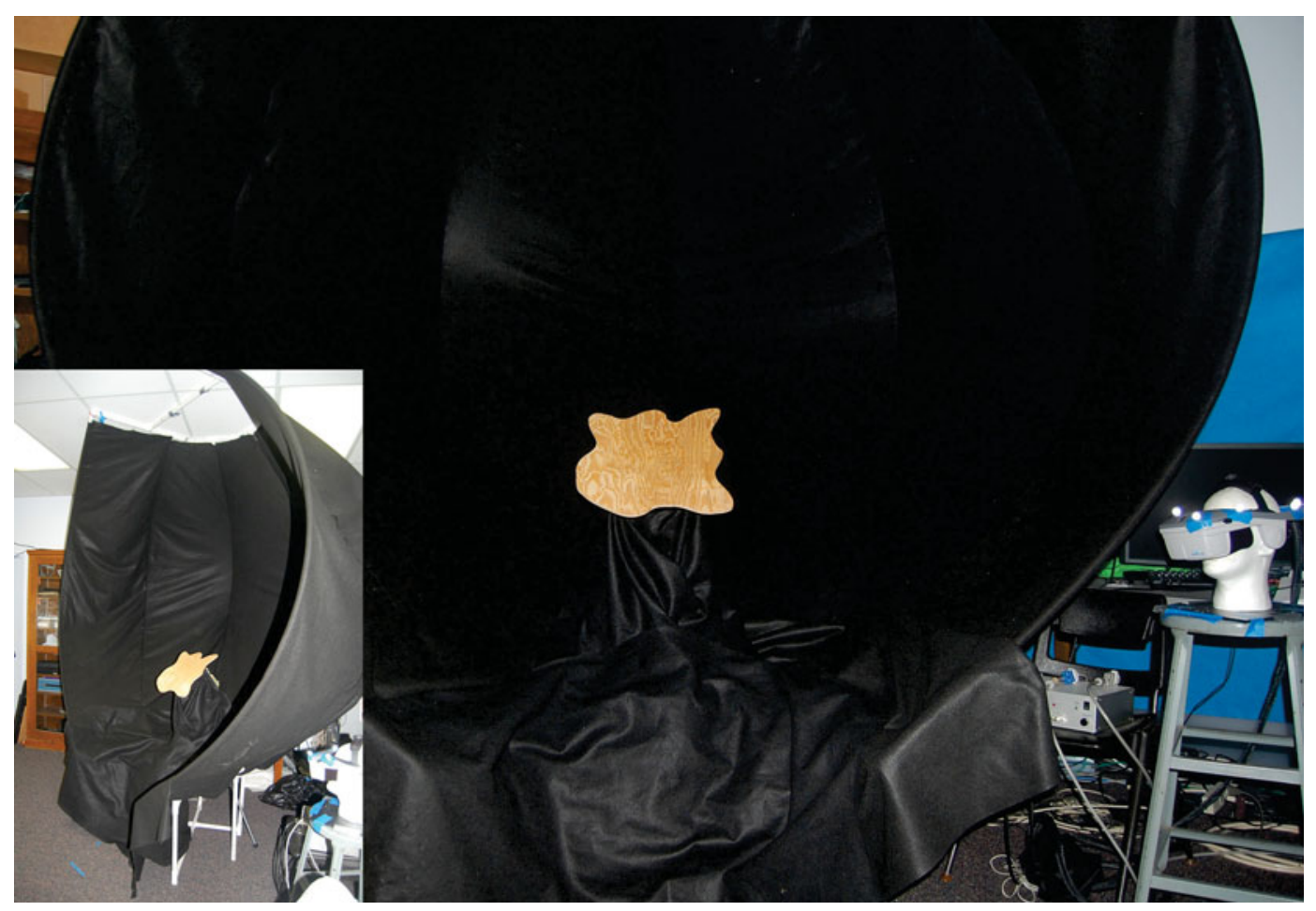

Figure 1. A sample wooden surface in the hemispheric enclosure used for Experiments 1, 2, 3, and 5. Participants stood within reach of the wooden surface. 

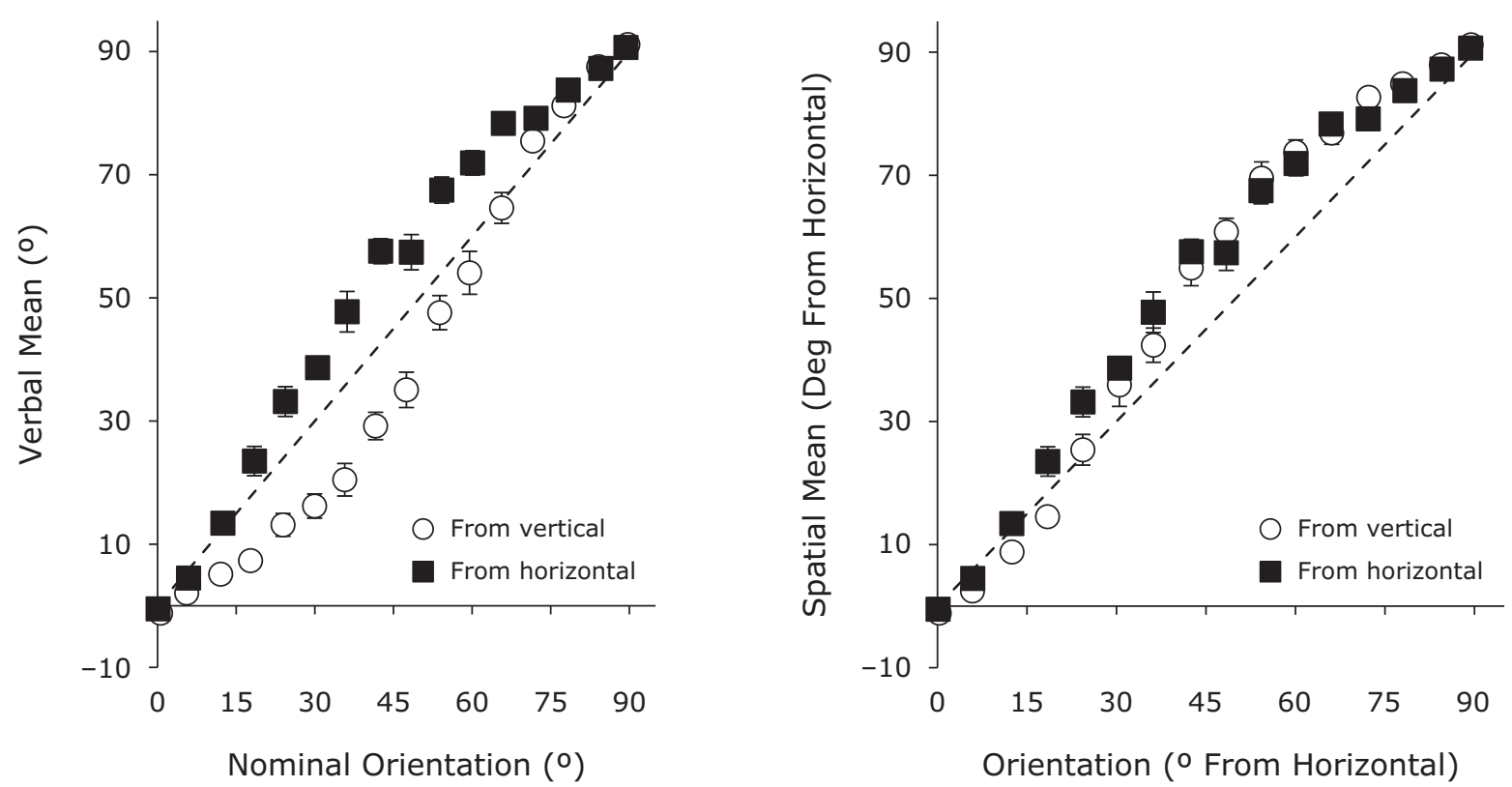

Figure 2. Results of Experiment 1. Left: Mean verbal estimates relative to the stipulated reference. Right: Estimates recoded in terms of deviation from horizontal. Standard errors of the means are shown.

minimum error for surface orientations frontal to gaze, near $53^{\circ}$, although the signed errors in Figure 3 show a small dip around, $50^{\circ}$ which might be caused by the frontal tendency.) If there is a perceptual "tendency" reflected in our data, it seems to be a "vertical" tendency.

Another way of looking at how verbal numeric judgments were used by participants is to plot histograms of verbal reports as a function of stimulus range. In Figure 4, responses are binned into the nearest $5^{\circ}$ category. For shallow slanted surfaces $\left(6^{\circ}-42^{\circ}\right.$ from horizontal), verbal reports in both conditions are distributed over a large range of numerical categories (roughly symmetric for the two cases), whereas for steep slanted surfaces $\left(48^{\circ}-84^{\circ}\right.$ from horizontal), verbal reports in both conditions are dramatically skewed toward the end of the scale representing "vertical." These data dramatically emphasize that in both

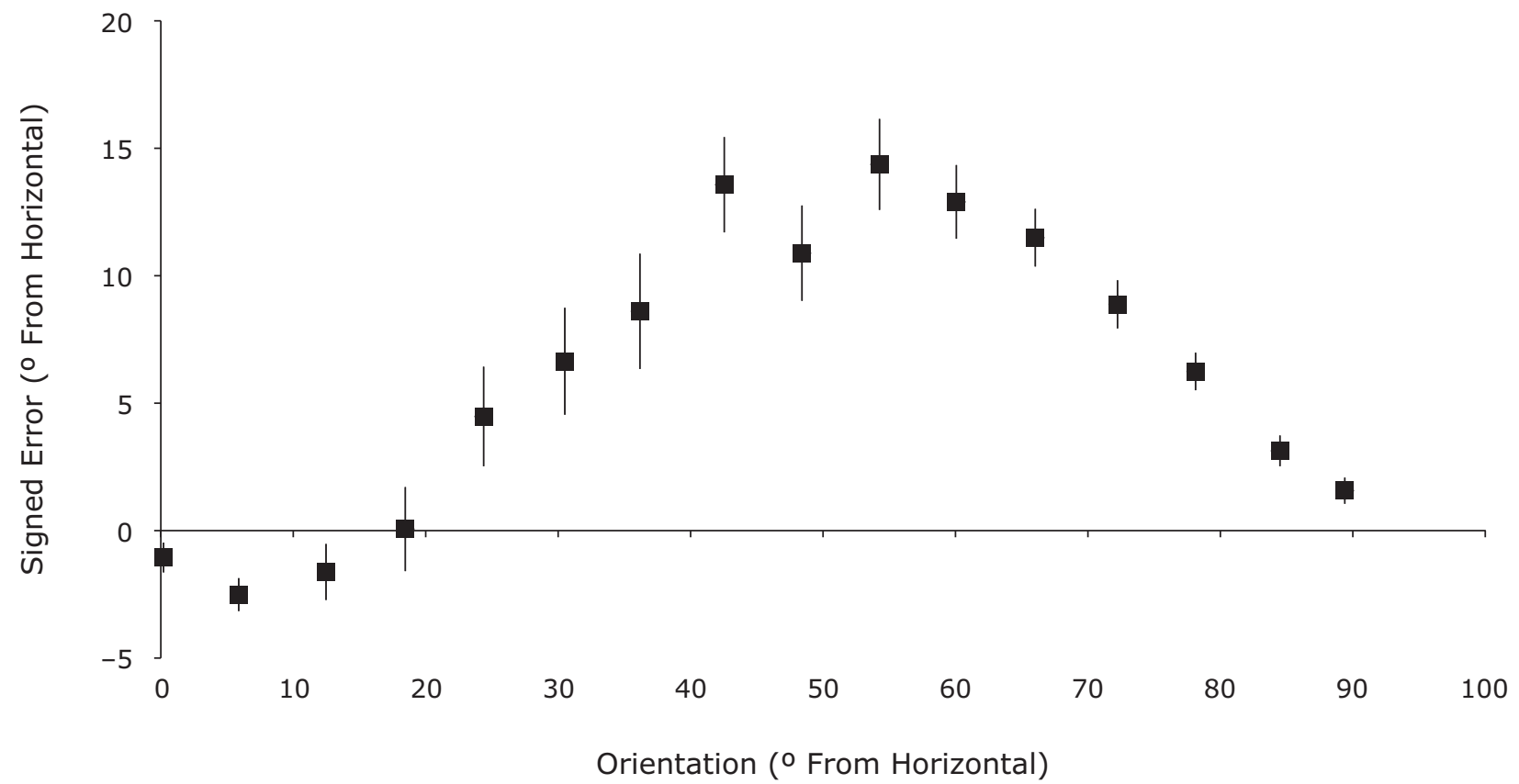

Figure 3. Signed errors in Experiment 1, with all judgments computed relative to horizontal. Standard errors of the means are shown. 

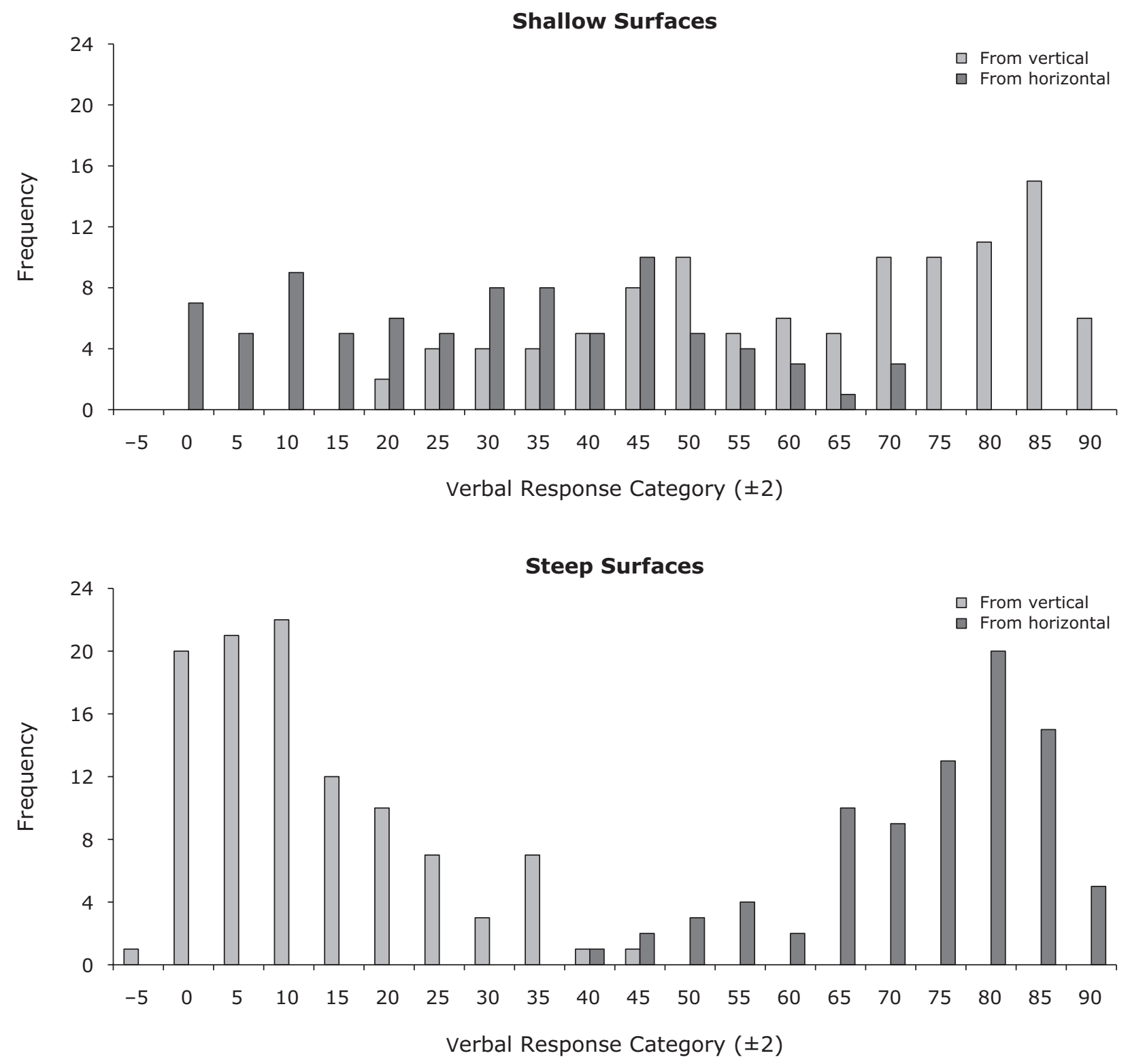

Figure 4. Histograms of verbal responses as a function of range of orientation in the two conditions of Experiment 1. The upper plot shows that for surfaces from $6^{\circ}$ to $42^{\circ}$ (shallow), verbal estimates are spread over a large range, whether estimated relative to vertical (light bars) or relative to horizontal (dark bars). The lower plot shows that for surfaces from $\mathbf{4 8}^{\circ}$ to $\mathbf{8 4}^{\circ}$ (steep), verbal estimates cluster near vertical (whether as low numbers "from vertical" or as high numbers "from horizontal").

coding schemes, the midpoint of the perceived range of angles is within the physical range of slants closer to horizontal than to vertical.

On the basis of these histograms, it seems unlikely that the observed spatial bias to see surfaces as steeper than they are could be the result of a numerical bias.

\section{EXPERIMENT 2}

\section{Numeric and Manual Estimates of Slant} for Visual Surfaces Within Reach

Was the spatial bias measured in Experiment 1 due to peculiarities of our stimuli? Using essentially the same apparatus, Durgin et al. (2010) found that freehand gestures accurately represented the slopes of surfaces within reach from $0^{\circ}$ to $48^{\circ}$ (when the gesture data were interpreted relative to the central axis of the hand, rather than the surface of the palm). To clarify whether the bias found in Experiment 1 existed for surfaces that could be gestured to appropriately, we replicated their gesturing experiment with the range extended to $90^{\circ}$. We first collected free-hand gestures and then, in a separate block of trials, verbal estimates from the same participants to ensure that calibrated action (hand orientation) was still accurate for these stimuli that were apparently misperceived. 


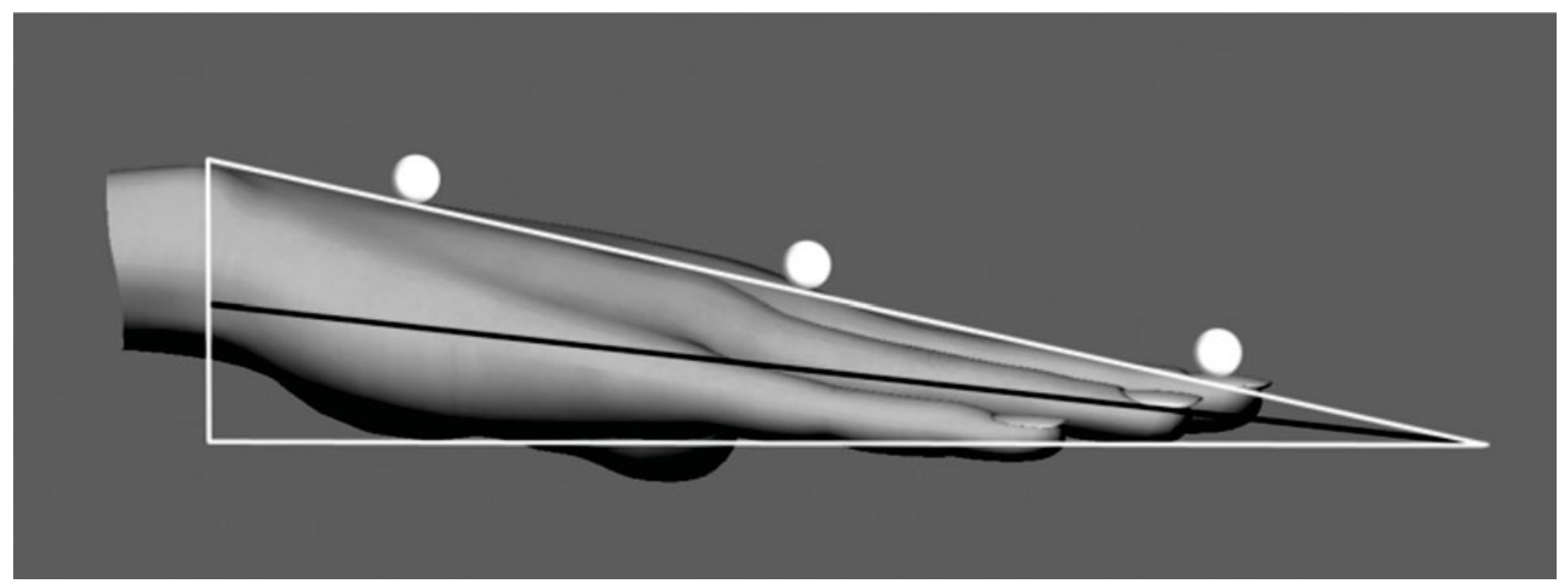

Figure 5. The human hand as a wedge (white triangle) with an angular thickness of about $13.5^{\circ}$ (Durgin, Hajnal, Li, Tonge, \& Stigliani, 2010). The circles represent tracked markers on the back of the hand. The black line represents the central orientation of the wedge formed between the back of a hand and the palm of that hand.

\section{Method}

Participants. Fourteen Swarthmore College students participated for pay.

Design. For each task, 16 geographical slants from $0^{\circ}$ to $90^{\circ}$ (by $6^{\circ}$ increments) were presented in random order, and a single estimate was collected on each trial, as in Experiment 1. The block of manual estimates was always conducted first, to reduce the likelihood of verbal interference. After the manual estimates were completed, the same set of slopes was repeated in a new random order, and numeric estimates (all relative to horizontal) were collected.

Apparatus. The stimuli were the same as those in Experiment 1. For the manual task, a Vicon optical tracking system was used to record angle measurements of the right palm at $200 \mathrm{~Hz}$ on the basis of four markers placed on the back of the hand. Between trials, the hand rested on a horizontal surface that was used to determine the angular offset between the back of the hand and the palm $\left(M=13.5^{\circ}\right)$. A restricting goggle was worn during the manual task (field of view: $100^{\circ} \times 50^{\circ}$ ) so that the hand would not be visible.

Procedure. The presentation of stimuli was similar to that in Experiment 1 . For the manual task, each participant was instructed to simply hold up his or her (unseen) right hand so as to make the palm of the hand parallel with the surface. During instruction, the experimenter demonstrated a posture in which the elbow was the primary joint used to orient the hand (although the wrist was not held rigid). When the participant indicated that the hand was in position, $1 \mathrm{sec}$ of orientation data (200 samples) was collected, and the participant was instructed to return his or her hand to the horizontal rest surface. After the 16 manual trials were completed, the restricting goggle was removed for the verbal trials that followed. The participants were asked to close their eyes between verbal trials.

\section{Results}

Free-hand task. The human hand approximates a wedge, with an angular thickness of about $13.5^{\circ}$, as shown in Figure 5. Because the intercept for the manual estimation data was, once again, offset by about $7^{\circ}$ when palm orientation was used (Durgin et al., 2010), the orientation of the center of the hand $\left(6.75^{\circ}\right.$ shallower than the palm) was computed and used for the analysis of manual gestures. The data for manual estimation of surface orientation are plotted in Figure 6 (left panel) as a function of actual surface orientation.
The overall data are well-fit by a linear function with a gain of 0.95 . This replicates the finding of Durgin et al. (2010) for the range from $0^{\circ}$ to $48^{\circ}$ and extends it to $90^{\circ}$. However, the signed errors, plotted in Figure 3B, suggest small biases in the manual estimates that result in slight range compression for the middle angles. The mean regression slope of estimates for slants from $18^{\circ}$ to $72^{\circ}(0.90)$ was marginally less than $1[t(13)=2.11, p=$ $.0549]$. The bias is consistent with the exaggeration of deviations from vertical and horizontal and, therefore, may reflect a property of the proprioceptive measure, rather than of the visual perception of slant.

That is, when giving manual responses, the participants may have exaggerated manual deviations from cardinal orientations in order to ensure that their hand clearly indicated that a surface was slanted, rather than being vertical or horizontal. Apart from this, the data show that, for these surfaces, calibrated manual actions were fairly accurate (within a few degrees, on average) and were unbiased overall (when coded in terms of the orientation of the main axis of the hand, rather than the palm). Whereas much of the manual data are qualitatively similar to what might be predicted by frontal tendency (minimum error at $45^{\circ}$ ), the accuracy at the cardinal orientations indicates excellent sensitivity to geographical vertical and horizontal, which would not be predicted by frontal tendency. It is for this reason that we interpret the compressed judgments in the middle range as resulting from exaggerated manual deviations from vertical and horizontal.

Verbal estimates. Verbal estimation data and signed errors are shown in Figure 7. Despite the accurate manual settings, verbal estimates continue to show that there is a marked vertical tendency in perceptual experience. As in Experiment 1, similar mean verbal estimates (of about $55^{\circ}$ ) are now given for the slants that are slightly less than frontal (ranging, in this experiment, from $36^{\circ}$ to $48^{\circ}$ ). 

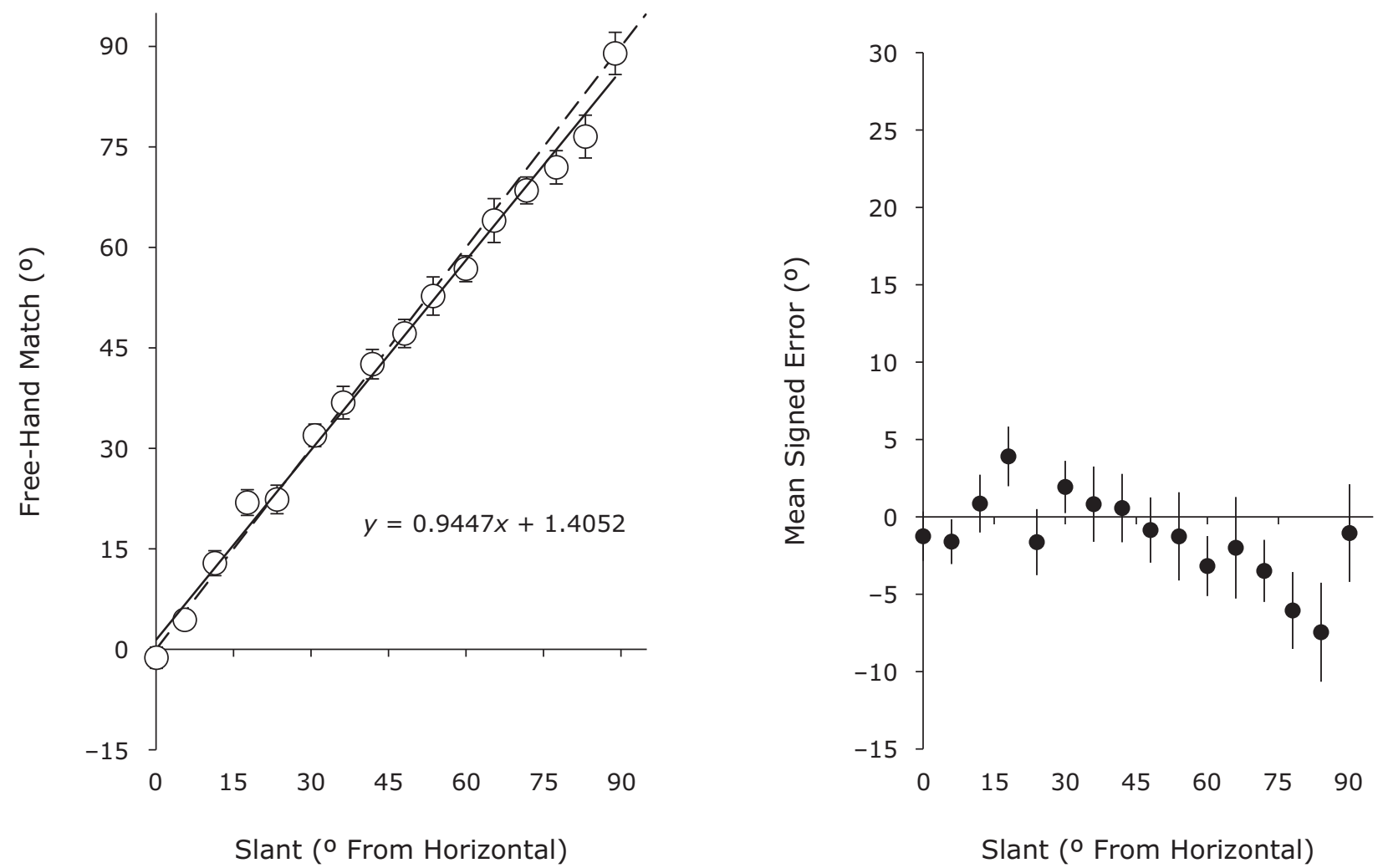

Figure 6. Results of the free-hand matching task in Experiment 3. Mean free-hand orientation is shown in the left panel, with mean signed error in the right panel. Standard errors of the means are shown.

Figure 8 shows a histogram of all the verbal responses given, binned by $5^{\circ}$ increments (i.e., the labeled angle plus or minus $2^{\circ}$ ). Data are shown only for slanted boards (i.e., not vertical or horizontal, which were typically judged accurately). Separate colors are used for physical slants below and above $45^{\circ}$. The data suggest that $85^{\circ}$ (i.e., "nearly vertical") is a very strong categorical attractor for steep angles. Estimates near $5^{\circ}$ (i.e., "nearly horizontal") also appear somewhat overrepresented locally.

One way to summarize this pattern of results is to note that the perceptual gain for slant is much higher for low slants than for high ones. Whereas changes in geographical slant from $12^{\circ}$ to $42^{\circ}$ were estimated with a gain of 1.5 , changes in geographical slant from $60^{\circ}$ to $90^{\circ}$ were estimated with a gain of only 0.46 . As we have seen in Experiment 1, this pattern of responses is not due to numerical bias.

\section{Discussion}

Gibson (1950) measured frontal tendency using hand gestures to reduced-cue stimuli (texture gradients). Here, we have measured a perceptual bias, under full-cue conditions, that is masked by hand gestures. Consistent with our view that manual actions are calibrated for near space slant, our data show that manual gestures were quite accurate, apart from avoiding cardinal axes, when slanted surfaces were presented. Nonetheless, even for individuals who responded accurately with their hand gestures, verbal numeric reports of perceptual experience suggest that their spatial perception is biased toward vertical: Small sloped surfaces seem steeper than they are. Even when a surface was viewed so that it was nearly frontal to gaze (e.g., a $48^{\circ}$ or $54^{\circ}$ slant), its geographical slant was overestimated by $10^{\circ}-15^{\circ}$, on average.

We emphasize that manual responses still showed evidence of category effects near the cardinal orientations. Participants represented "vertical" accurately, on average, but seemed to avoid setting their hand too close to vertical when the reference surface was categorically "slanted" (i.e., $84^{\circ}$ or less). We interpret this as an idiosyncrasy of the output measure (the intentional use of gesture), rather as than a reflection of visual experience, because it is consistent with a limitation of analogue outputs in general. The precision afforded by digital (verbal) outputs allows even " $89^{\circ}$ " to represent "nearly but not quite vertical" without ambiguity.

Vertical tendency. In classic studies of perceived slant, the concept of frontal tendency was introduced to capture the phenomenon that small deviations from frontal orientations specified by texture were underestimated (Gibson, 1950). In such studies, gaze was forward, and slant was conceptualized with respect to the line of gaze (optical slant). In the present study, gaze was directed downward at roughly a $40^{\circ}$ angle toward the surfaces, so that optical slant was frontal for surfaces of about $50^{\circ}$. That is, deviations in optical slant were roughly symmetrical about 


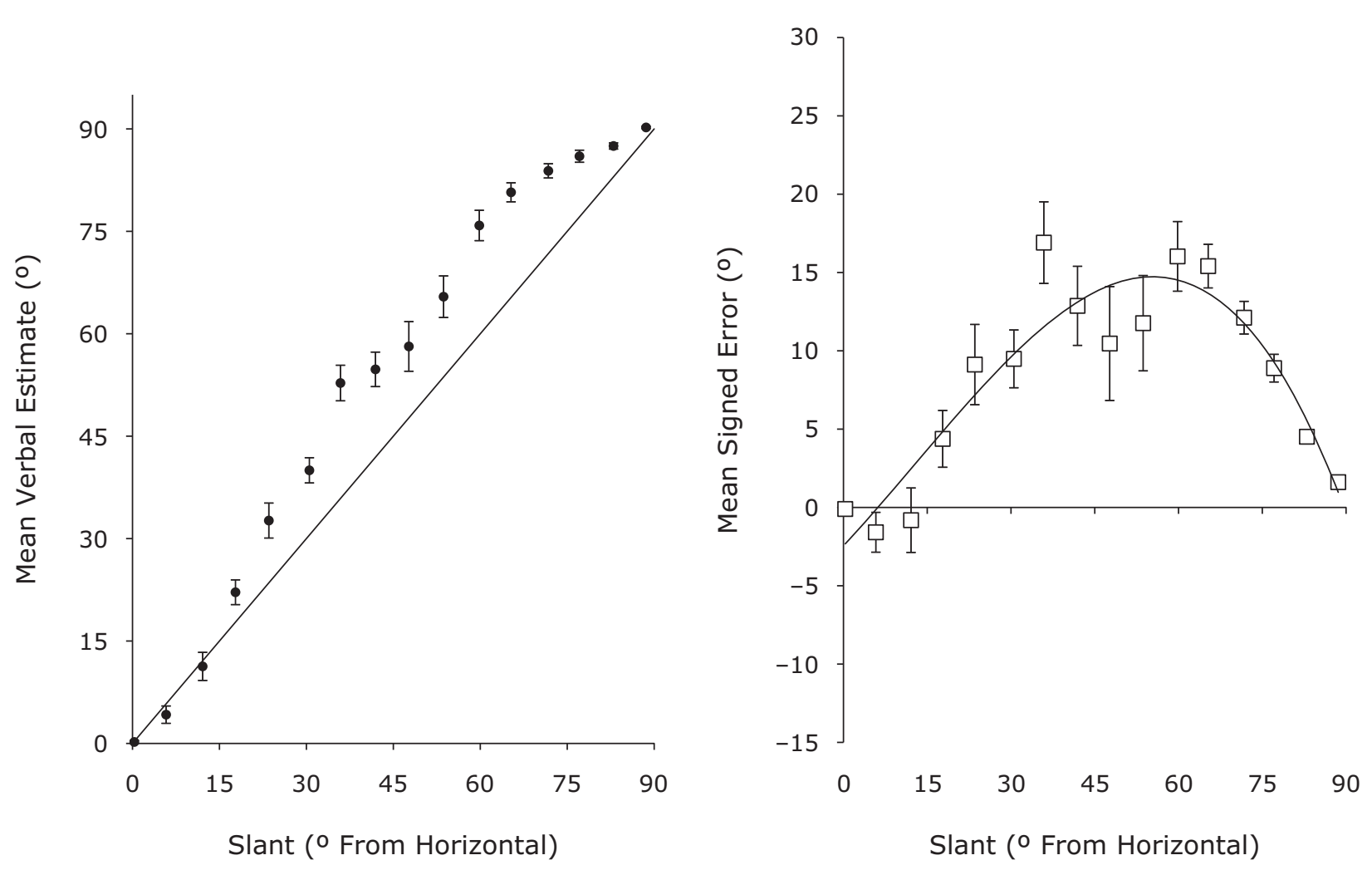

Figure 7. Verbal estimation data from Experiment 2. The left panel shows mean estimates. The right panel shows the data as signed error, with a quadratic fit. Standard deviations of the means are shown.

the surface that had a geographical slant of $50^{\circ}$ (depending on the height of the observer). But, whereas manual estimates were quite accurate, verbal surface orientation estimates were not the most accurate when the optical slant was fully frontal. Thus, the present data suggest the existence of a vertical tendency in the spatial representation of geographical slant. We argue that this perceptual bias is hidden by the manual responses because manual actions for objects within reach are calibrated by experience (Harris, 1963). We accept, of course, that our data do not discriminate between the calibration hypothesis and the hypothesis that the brain maintains two (or more) separate representations of near space, but we emphasize that the different response patterns do not, in themselves, imply two different representations, because action can be calibrated (physically accurate) even when based on a distorted perceptual representation (see also Durgin et al., 2010; Hajnal et al., in press).

\section{EXPERIMENT 3 \\ Numeric Estimates of Slant With Gaze Horizontal}

To confirm that the spatial biases found in Experiments 1 and 2 were not somehow due to the declined direction of gaze, we replicated the verbal numeric estimation task with participants situated so that they viewed the reference surfaces along a horizontal line of sight.

\section{Method}

The method was similar in most respects to that in Experiment 1. The participants were 9 undergraduate students who had not participated in the previous experiments. In this experiment, the participants were seated, and a chinrest was used to stabilize the head, with the eyes level with the center of the reference surfaces. The viewing distance to the center of the boards was $55 \mathrm{~cm}$. Because gaze was horizontal, the horizontal surface orientation was omitted from the design. The 15 remaining orientations from $6^{\circ}$ to $90^{\circ}$ were presented twice in random order in two complete blocks of 15 trials. Only verbal numeric responses were collected. All the participants made estimates in degrees relative to horizontal.

\section{Results and Discussion}

The data are shown in Figure 9. Mean verbal slant estimates and mean signed error are plotted as function of physical slant. The signed error function is similar to the function found in Experiments 1 and 2 for verbal numerical judgments in most respects and, thus, appears to be a function of geographical slant (vertical tendency), rather than of optical slant (frontal tendency).

In this experiment, vertical tendency and frontal tendency coincided. The vertical tendency in numeric estimates of visually perceived geographical slant was replicated with gaze forward, but the flattening of the error function near $45^{\circ}$ in Experiments 1 and 2 disappeared. It is possible that the flattening found in Experiments 1 and 2 was due to frontal tendency (Gibson, 1950); however, the principal bias function is independent of direction of gaze and seems to be related to the categorical 


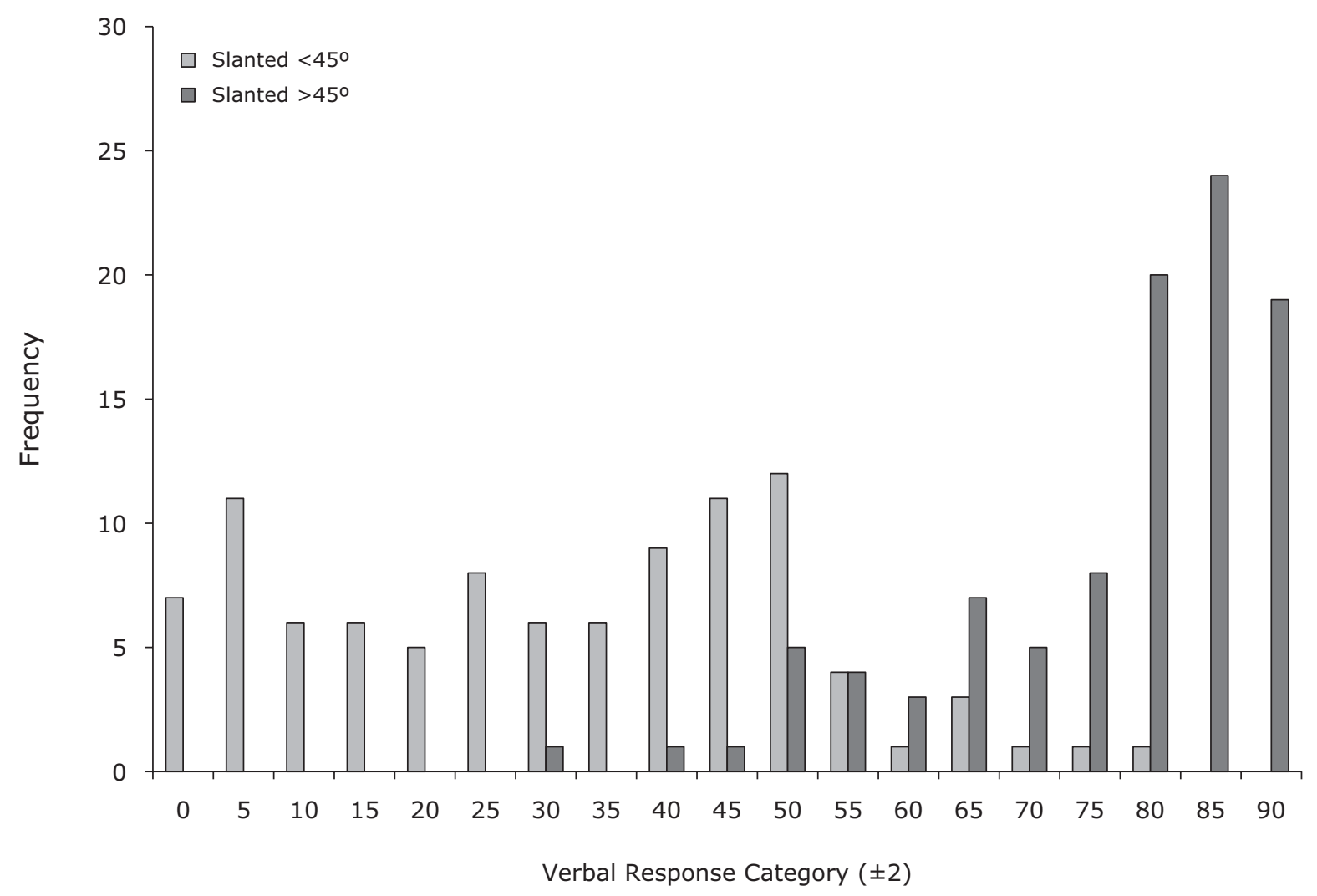

Figure 8. Histogram of all the verbal responses in Experiment 2 for surfaces that were neither horizontal nor vertical. As in Experiment 1, there was a strong tendency to label surfaces slanted more than $45^{\circ}$ as nearly vertical.

reference frames imposed by the viewers (i.e., horizontal and vertical).

\section{EXPERIMENT 4 Haptic Slant Perception}

Are the biases we have identified visual or are they spatial? Hajnal et al. (in press) showed that when ramps are stood upon, they feel much steeper than they are. That is, the haptic experience of the orientation of surfaces underfoot is exaggerated, just as is the perceived slant of hills. Hajnal et al. measured this overestimation both with verbal numeric estimates and with hand gestures (which have no reason to be calibrated for surfaces, such as ramps, that are not within reach of the hands). The exaggeration was also present in congenitally blind participants.

So far, we have shown that the visual perception of the slants of near surfaces are quite biased even though the pantomime action of setting one's hand parallel to near surfaces shows good calibration. If surfaces look steeper than they are but hand actions are calibrated to this distorted perception, it seems likely that surfaces will also feel steeper than they are when contacted by hand. To test this, we had blindfolded participants assess the orientation of wooden surfaces by placing a hand flat on each surface and verbally estimating its surface orientation.

\section{Method}

Participants. Seven students participated, with consent, as part of a class laboratory.

Design. Two arm postures were tested to ensure that the results were not due to a specific posture. Arm posture was blocked and varied within subjects. Sixteen surface orientations from $0^{\circ}$ to $45^{\circ}$ by $3^{\circ}$ increments were tested in random order for each arm posture. Posture order was varied between subjects.

Arm postures. The two arm postures for contacting the surface were straight and bent. In the straight-arm posture, the arm was to be held straight (elbow extended) and approximately horizontal from the shoulder while the hand made contact with the surface and pivoted at the wrist. The range of surface orientations used accommodated the limits of comfortable wrist flexion. In the bent-arm posture, the elbow was held out laterally from the shoulder, and the hand and forearm were held forward, so that the hand and forearm could pivot using the shoulder joint.

As was discussed above, Durgin et al. (2010) found that proprioception of wrist flexion was greatly exaggerated and that this caused a misperception of palm board orientation. However, in the present experiment, the hand interacted with a stable surface on each trial that resisted the forces of the hand (unlike a palm board). When pressing one's hand against a fixed, resistive surface, forces applied normal to the surface, via the forearm, can apply torque to the hand and cause the hand/wrist to comply to the orientation of the fixed surface (wrist rotation is, in some sense, "passive"). In contrast, if the surface is not oriented rigidly, the wrist must actively supply torque to rotate the hand/surface or to balance the torque produced by force from the forearm. Thus, the haptic perception of an oriented stable surface might be quite different from the haptic perception of palm board orientation. 


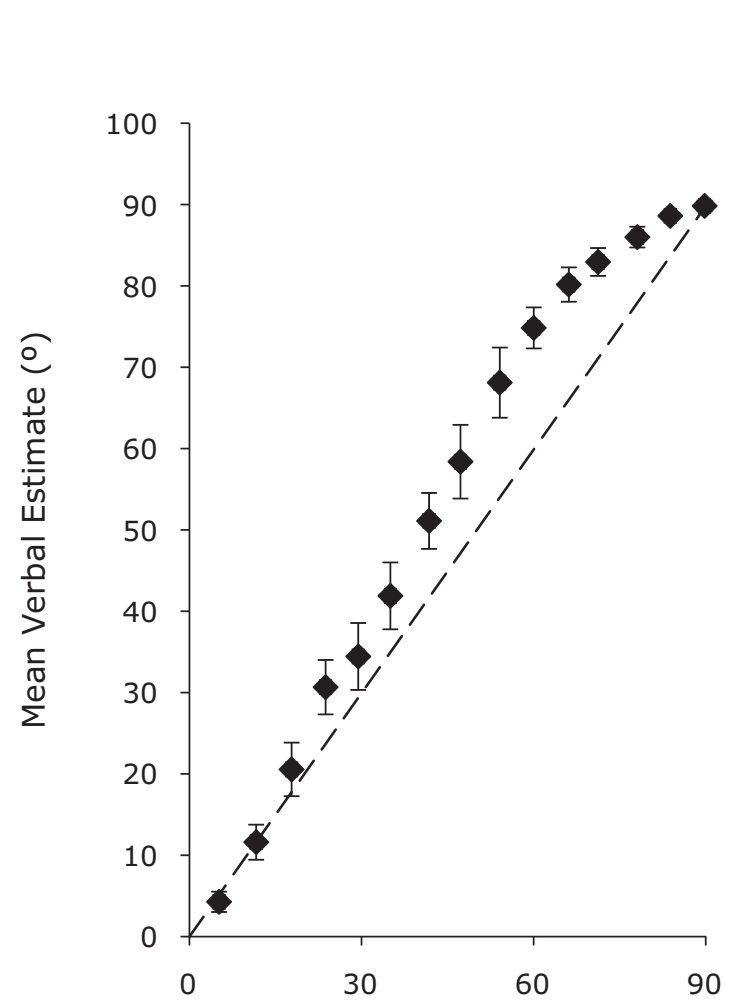

Physical Slope Presented ( $\left.{ }^{\circ}\right)$

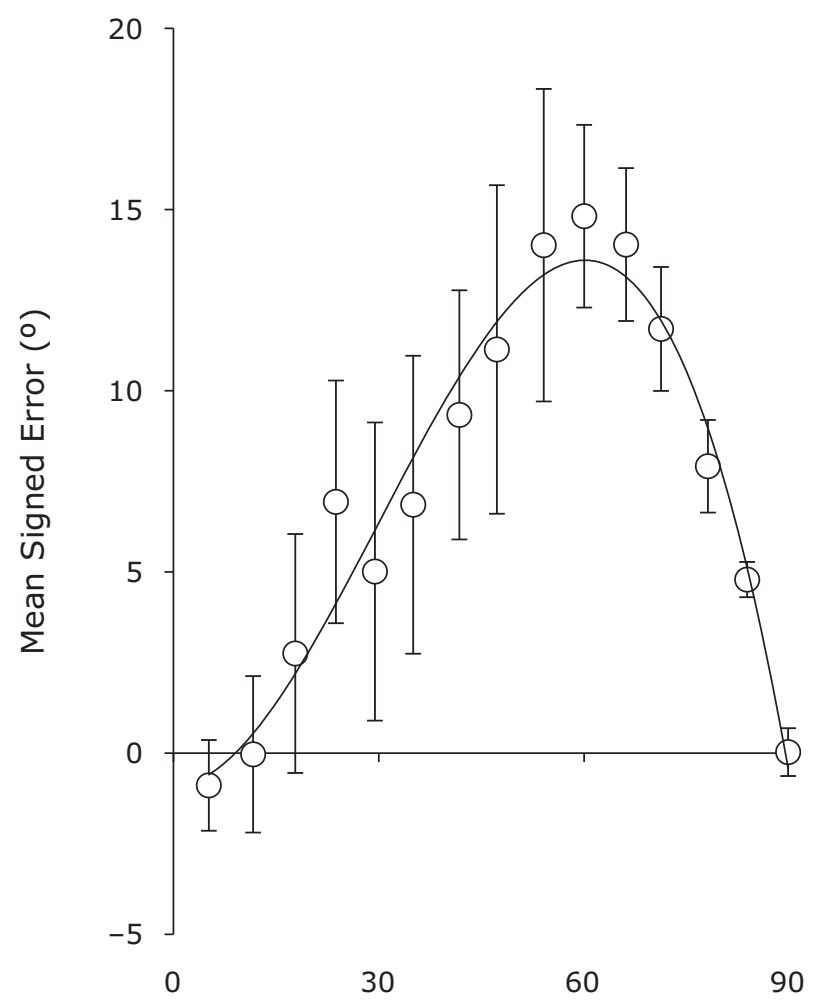

Physical Slope Presented ( $\left.{ }^{\circ}\right)$

Figure 9. Results of Experiment 3: Verbal slant estimates relative to horizontal (left) and signed error (right) with gaze forward. Standard errors of the means are shown. A quadratic fit is shown.

Apparatus. A large wooden surface (approximately three times as large as the surfaces used for the visual experiments, so that blindfolded aim was not crucial) was mounted on the slope device used in Experiments 1 and 2 and raised to shoulder level. An inclinometer was used to assess surface orientation (to within $0.2^{\circ}$ ) while the hand of the participant was in contact with the surface. The participants wore a plush sleep mask as a blindfold during the experiment.

Procedure. The participants were initially allowed to see the (horizontally oriented) wooden surface they would be touching and were instructed concerning the posture to be used. They were not permitted to touch the surface until they had been blindfolded. On each trial, one experimenter set and measured the surface orientation while the other experimenter instructed the participant and recorded verbal estimates of surface orientation. Sixteen estimates were made with one arm posture, and then 16 with the other.

\section{Results}

Numeric verbal estimates of surface orientation are shown in the left panel of Figure 10, separated by arm posture. Because the graph suggests that there was no systematic effect of posture (and statistical tests of means and regression slopes revealed no reliable differences), signed errors are shown for the combined data in the right panel. The error function in haptic perception bears a close resemblance to the error functions measured from visual perception: There is a tendency to slightly underestimate small deviations from horizontal but an increasing signed error function in the range from $10^{\circ}$ to $45^{\circ}$. In other words, the haptic perception of surface orientation shows approximately the same spatial bias as that observed in Experiments 1-3 for the visual perception of surface orientation.

\section{Discussion}

The approximate match between haptic perception and visual perception likely derives from the calibration of one sense to the other (although the direction of that calibration is not specified). However, if the bias in haptic perception is so similar to the bias in visual perception, why did Durgin et al. (2010) find that palm boards were set so low when matched to near reachable surfaces? Although a full answer goes beyond the scope of this report, it seems likely that haptic contact with a stable surface can depend on passive accommodation of the wrist joint to torque produced by linear forces exerted to the lower part of the hand along the forearm; these forces would be matched by forces exerted by the stable surface against the finger tips. In contrast, for a rotatable surface, such as a palm board, the dynamics are quite different, and this apparently leads to a different perceptual experience.

Bhalla and Proffitt (1999) reported data for palm board settings in response to verbal targets. Participants (in their Experiment 2) were asked to set a palm board (without viewing it) to each of eight different numerical angles $\left(5^{\circ}, 10^{\circ}, 15^{\circ}, 20^{\circ}, 30^{\circ}, 45^{\circ}, 60^{\circ}\right.$, and $\left.75^{\circ}\right)$. It is possible to 

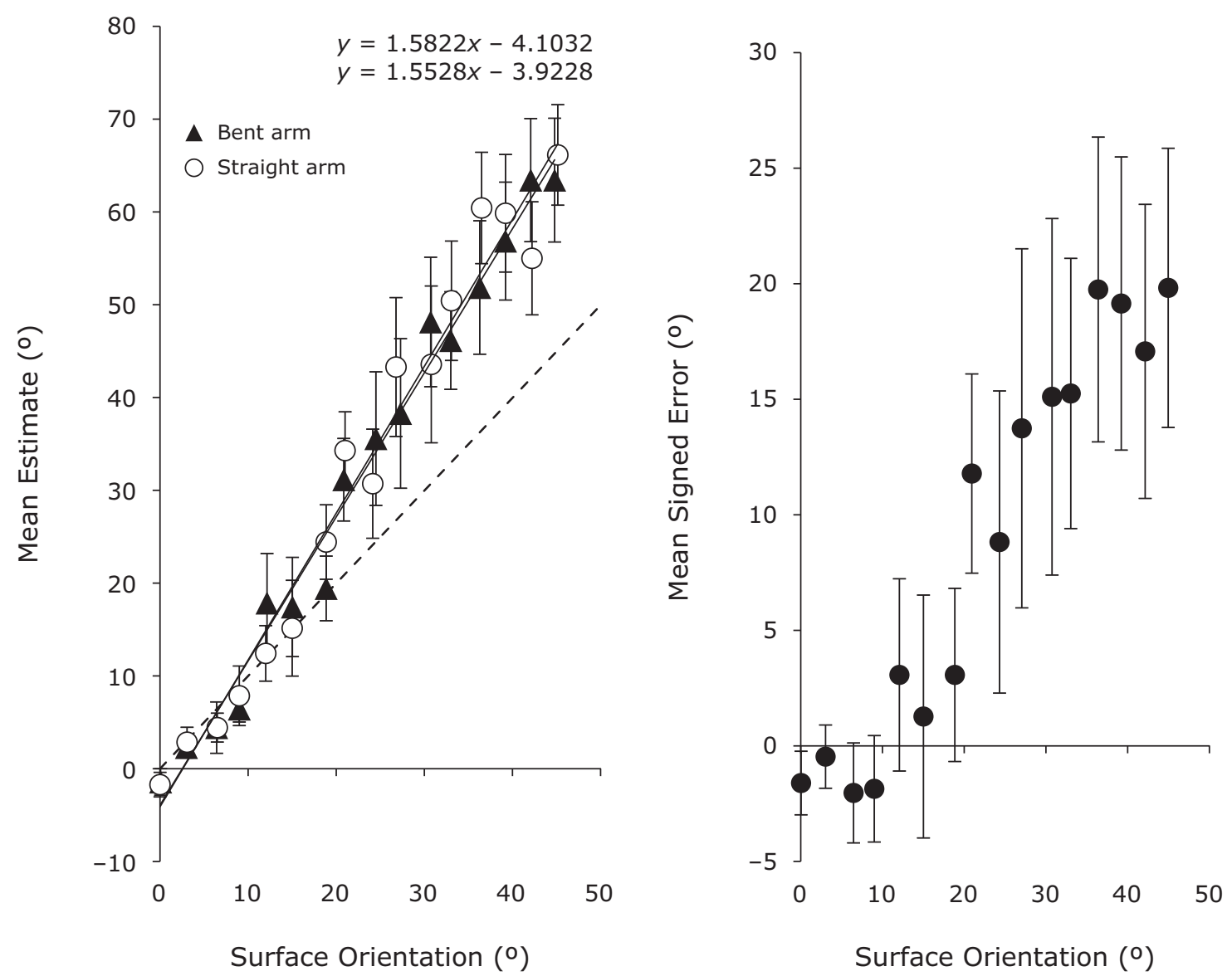

Figure 10. Mean estimates of haptic surface orientation (left) in Experiment 4 as a function of posture used for the range $0^{\circ}-45^{\circ}$. Mean signed error in this range is also shown (right). Error bars represent standard errors of the means.

compare the "numeric" perception of their palm board with the mean verbal numeric estimates measured here for haptic perception of stable surfaces by plotting their verbal numeric target along the ordinate and their measured physical palm board setting along the abscissa, as shown in Figure 11.

As predicted by our dynamics account, the two plots diverge as the required rotation of the palm board surface increases. In the case of the rotatable palm board, the resistive torque of the wrist must be countered somewhat directly (i.e., by actively flexing the wrist), whereas in the case of a stable surface, the resistive torque of the wrist can be overcome by simple forward force against the surface. Setting a palm board is not equivalent to a direct haptic matching task and suggests that replacing a palm board with a haptically rigid surface would produce different (better calibrated) results. One could create a robotic device that would allow the palm board to be rotated under the control of a motor, rather than the hand, in order to create such a haptic matching task. The palm board production data from Bhalla and Proffitt (1999), however, are consistent with the observation of Durgin et al. (2010) that palm boards are set much too low for surfaces within reach, because palm boards, like hills, are consciously perceived as being much steeper than they are.

\section{EXPERIMENT 5 \\ The Perceived Bisection Point Between Vertical and Horizontal}

Can it really be that people misperceive near surface orientations so consistently, or is this just an artifact of the method of collecting verbal numerical estimates? In order to remove the likelihood of verbal influence, we simplified the task to the problem of deciding whether a given surface was closer to vertical or to horizontal. As we have seen, there is little systematic perceptual bias evident in verbal reports of the categories of vertical and horizontal. However, if the conclusions we have drawn from our verbal methods are correct, we should predict that a geographical slant of about $35^{\circ}$ from horizontal (typically described as " $45^{\circ}$ " in our prior experiments) will appear to observers to be equally close to vertical and to horizontal. As in Experiments 1 and 2, we presented the surfaces at chest level so that gaze was downward.

\section{Method}

Participants. Six students (4 of them female) participated in partial fulfillment of a course requirement. None had previously participated in our experiments on slant perception. Mean eye height was $157 \mathrm{~cm}$. 


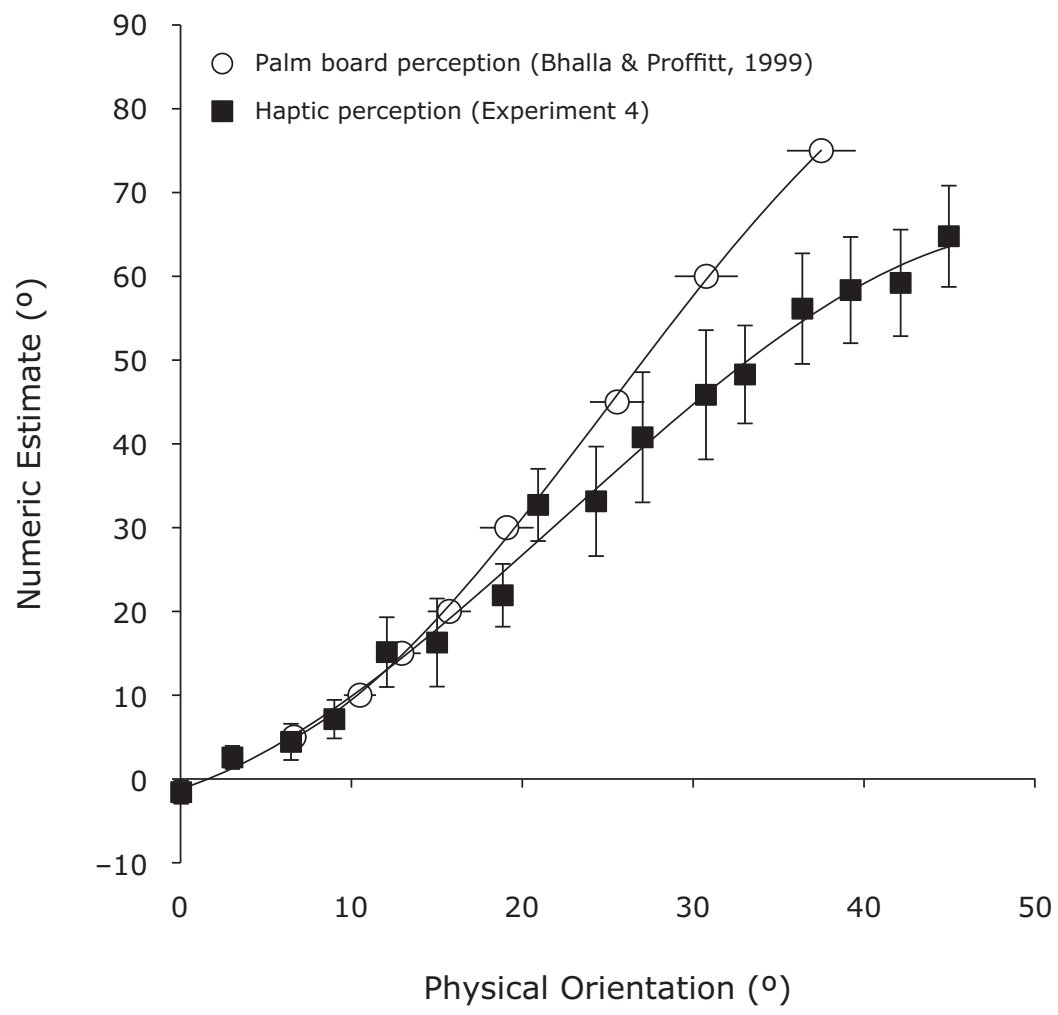

Figure 11. A comparison of the haptic perception of a stable surface (Experiment 4) with the perceived orientation of a rotatable palm board (Bhalla \& Proffitt, 1999, Table 4). The palm board production data are from the baseline condition in Experiment 2 of Bhalla and Proffitt (1999). Cubic fits are shown. Standard errors of the means are shown, along with cubic fit lines.

Apparatus. The stimuli and context were like those in the prior experiments. A computer program interactively controlled the sequence of wooden slopes to be presented.

Design and Procedure. A computer-controlled up-down staircase procedure was used with three staircases (series of contingent trials) that were randomly interleaved. On each trial, a single slant was presented, and a two-alternative forced choice response was collected by means of a keyboard. An up-arrow response indicated that the surface appeared nearer to vertical than to horizontal. The down-arrow indicated that it appeared nearer to horizontal than to vertical. Responses were recorded, and the value for that staircase was adjusted by $15^{\circ}$ up or down, depending on the response given. One staircase started at $20^{\circ}$, a second at $70^{\circ}$, and a third at $45^{\circ}$. Thus, as a whole, the procedure sampled the space of possible slopes by $5^{\circ}$ increments and was initially unbiased. Two trials from each of the three staircases were randomly ordered in each of 10 blocks, for a total of 60 trials.

\section{Results and Discussion}

Psychometric functions for each of the 6 observers are shown in Figure 12. The mean point of subjective equidistance (PSE) between vertical and horizontal was $34.3^{\circ}$ from horizontal, consistent with verbal reports in our prior experiments. The perception of intermediate surface orientation in near space is biased toward vertical, such that a surface that is only $34^{\circ}$ from horizontal appears to be intermediate between horizontal and vertical. This shows that when surfaces of this orientation were described as being about $45^{\circ}$ by the participants in Experiments 1-4, they really meant to indicate that they seemed to bisect the range between horizontal and vertical.

\section{GENERAL DISCUSSION}

We have shown that there is systematic perceptual bias in the perceived geographical slant of surfaces that are within reach of the hand. The spatial form of the bias (vertical tendency) measured by verbal numeric estimation is essentially the same whether angle judgments are made relative to horizontal or to vertical and is remarkably independent of the direction of gaze. Moreover, direct judgments of vertical/horizontal bisection confirm that the bias does not depend on numerical estimation. We have documented similar biases in haptic perception, and we have shown that these biases are not due to frontal tendency (Gibson, 1950). We consider these biases categori$\mathrm{cal}$, because they do not affect the cardinal orientations of vertical and horizontal. Rather, they seem to exist in the space between these anchoring categories.

It is worth pointing out that horizontal and vertical are not spatially symmetrical categories: Whereas all horizontal planes (such as floors and ceilings) are parallel to one another, vertical planes (such as walls) need not be. Vertical is fundamentally a vector orientation (defined by gravity), whereas horizontal is fundamentally planar in a 3-D environment. This asymmetry means that whereas the 
Logistic: PSE = 36.8; JND $=2.9$

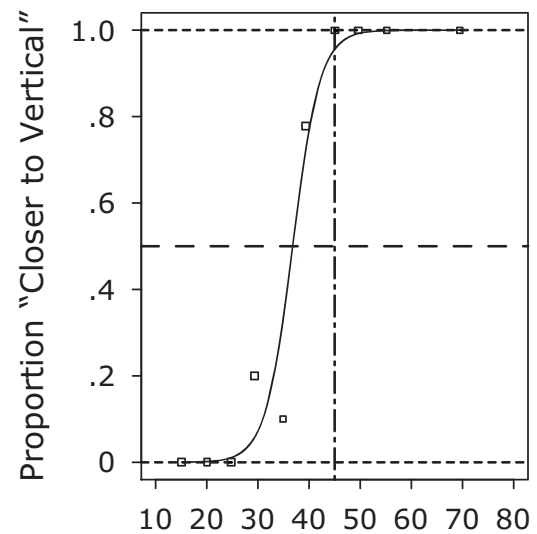

Geographical Slant ( $\left.{ }^{\circ}\right)$
Logistic: PSE = 30; JND $=2.3$

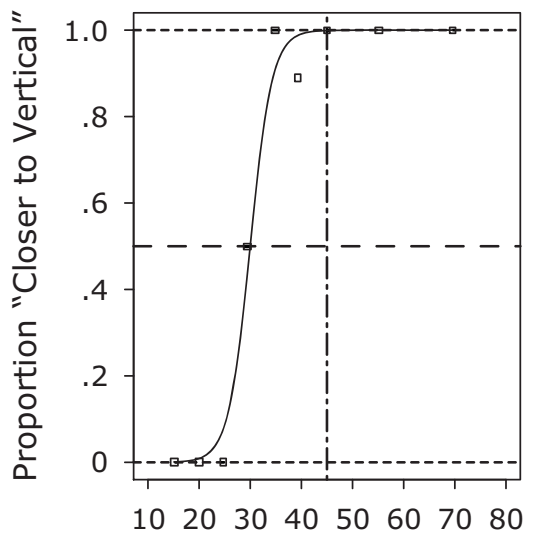

Geographical Slant ( $\left.{ }^{\circ}\right)$
Logistic: PSE = 37.2; JND $=\mathbf{3 . 8}$

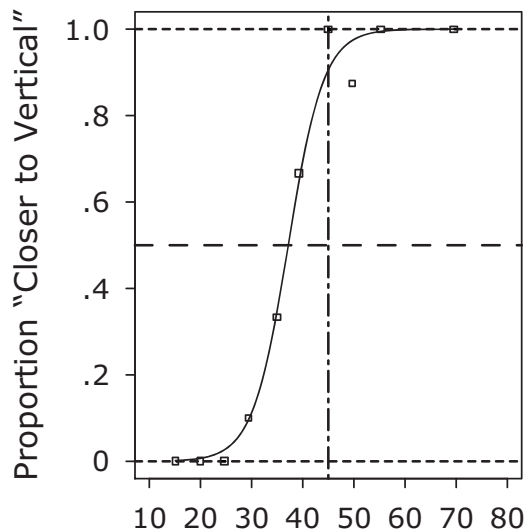

Geographical Slant ( $\left.{ }^{\circ}\right)$
Logistic: PSE = 33.8; JND $=4.6$

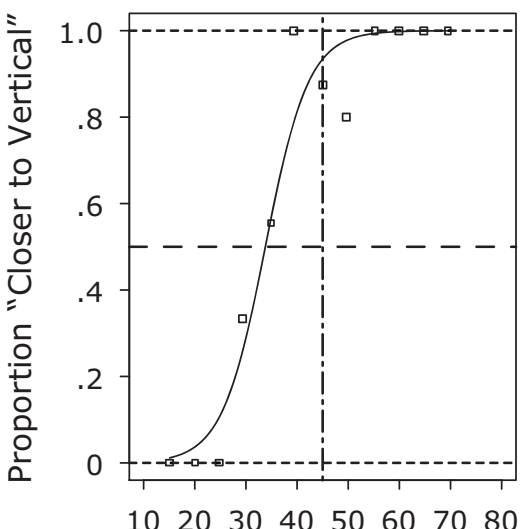

Geographical Slant ( $\left.{ }^{\circ}\right)$
Logistic: PSE = 33.8; JND $=1.8$

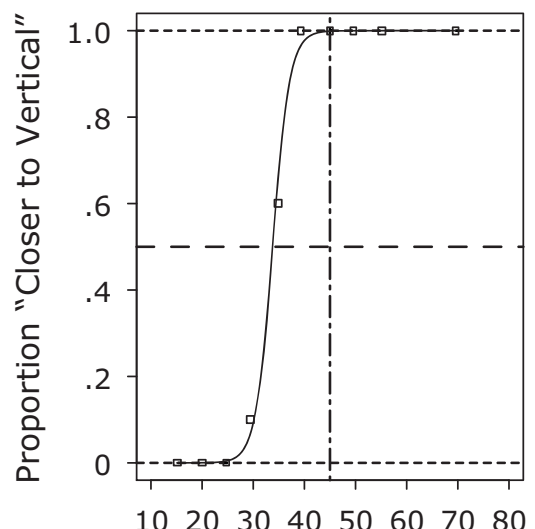

Geographical Slant ( $\left.{ }^{\circ}\right)$
Logistic: PSE = 34.4; JND $=0.2$

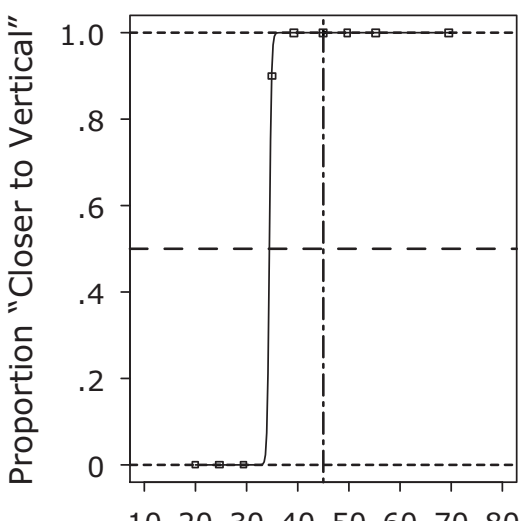

$102030 \quad 40506070 \quad 80$

Geographical Slant ( $\left.{ }^{\circ}\right)$

Figure 12. Psychometric functions for each of the 6 observers in Experiment 5. In each case, the point of subjective equidistance (PSE) from vertical and horizontal is about $35^{\circ}$. Each plot is based on 60 trials. JND, just-noticeable difference.

ground plane is everywhere horizontal, the walls around us, although vertical, are normally laterally tilted with respect to gaze and, therefore, not prototypically vertical unless we are directly facing them. It may be partly for this reason that the perception of surface slant appears to be more sensitive to deviations from horizontal than from vertical.

A number of authors have sought to understand biases in memory for 2-D orientation and slant in terms of category effects (Engebretson \& Huttenlocher, 1996; Haun, Allen, \& Wedell, 2005; Huttenlocher, Hedges, \& Duncan, 1991; Tversky \& Schiano, 1989). Wolfe, Friedman-Hill, Stewart, and O'Connell (1992) suggested that the (2-D) categories of steep and shallow play a role in visual search for 2-D orientation. Simmering, Spencer, and Schöner (2006) suggested that oriented reference frames, such as axes of symmetry, can serve as repellers and attractors in remembered orientation (see also Spencer, Simmering, \& Schutte, 2006).
Our perceptual data suggest that similar kinds of categorical reference frames (the horizontal and vertical reference frames in the present case) influence the perceptual experience of surface slant. The fact that geographical vertical and horizontal seemed to serve as solid anchors (categories) for perceptual judgments in our experiments (even when gaze was angled downward at our surfaces) illustrates the importance of these references for the specification of surface orientation. The asymmetrical bias away from horizontal and toward vertical (or steep) points to the importance of categorical reference frames in the perceptual experience of surface slant.

Vertical tendency seems to be pervasive in human slant perception. Hajnal et al. (in press; see also Durgin et al., 2009) had people judge the slopes of ramps while standing on them. They found that the pedal perception of geographical slant was quite exaggerated (they tested 


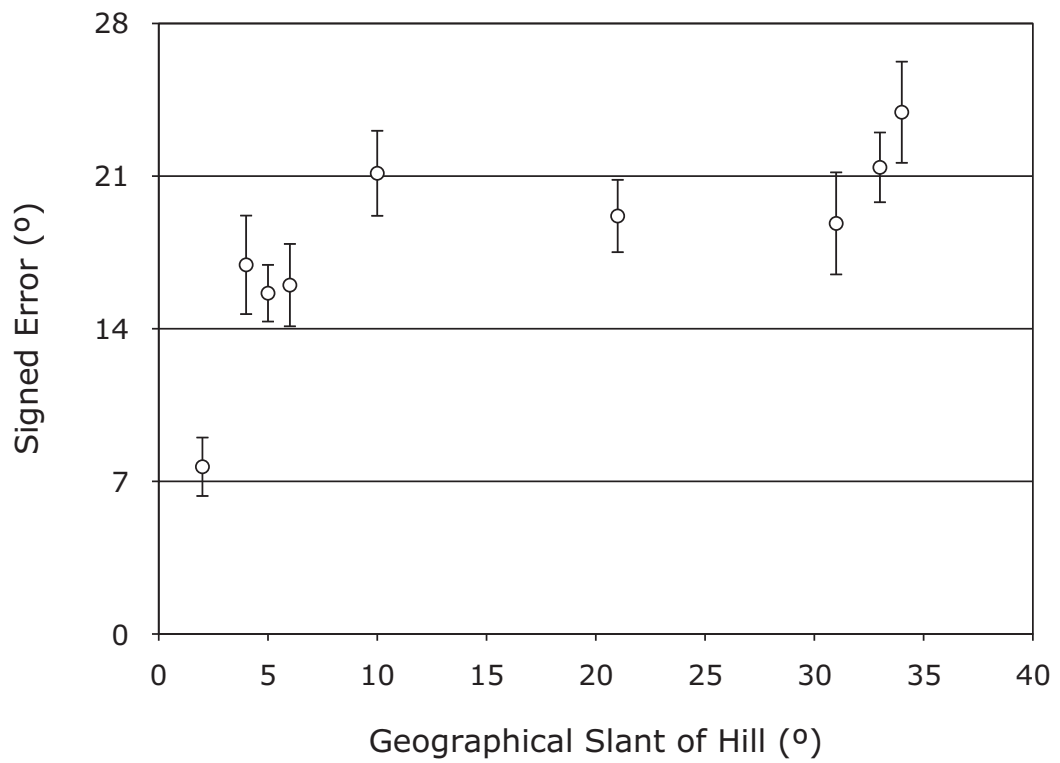

Figure 13. Signed error functions for verbal estimation data from nine outdoor hills (computed from Table 2 in Bhalla \& Proffitt, 1999). Hills greater than $10^{\circ}$ were grassy embankments. Lower hills were roads or sidewalks.

the range of slants from $4^{\circ}$ to $16^{\circ}$ ). Hajnal et al. showed that this exaggeration of perceived slant was present in the congenitally blind as well, indicating that it was not of visual origin. Of course, humans are terrestrial species whose main mechanical contact for locomotion is with the ground surface. For a species that spent most of its time on or near vertical surfaces, a different kind of perceptual bias may apply. However, even pigeons (Nardi \& Bingham, 2009) and tree-climbing hermit crabs (Dunham \& Schöne, 1984) are sensitive to ground surface slant.

Although vertical tendency was not evident in manual gestures employing a free hand (Experiment 2), we have emphasized that calibrated actions ought not to be informative about stable biases in perceptual experience. Although several reports have argued for dissociations between conscious perception of geographical slant and perception for action (e.g., Bhalla \& Proffitt, 1999; Creem \& Proffitt, 1998; Proffitt, 2006; Proffitt et al., 1995) these reports depended on characterizing palm board measures (rotation of a unseen board by hand) as visually guided actions. This characterization has since been falsified (Durgin et al., 2010).

The present dissociation between free-hand gestures and direct measures of perception thus does not imply the existence of two separate perceptual representations. Instead, one promising theory is that the precision of motor actions is aided by being calibrated to an expanded perceptual scale for the most commonly encountered orientations. We have not measured the distribution of surface slants in natural settings, but, due to the powerful effect of gravity and the asymmetry between vertical and horizontal discussed above, it is likely that far more slanted surfaces are nearly horizontal than are nearly vertical. A scale expansion of the range near horizontal would therefore be functional.
Li and Durgin (2009) and Hajnal et al. (in press) have also argued that linear perceptual expansion of a portion of the range of slants may have functional utility in the control of action (Durgin, 2009). It can be stated, that for locomotor surfaces, orientations of less than about $10^{\circ}$ represent the vast majority of encountered slants. (The famously steep Lombard Street in San Francisco is on a $15^{\circ}$ hill-i.e., a $27 \%$ grade.) In Figure 13, we have plotted existing verbal numeric estimation data for large-scale hills in terms of signed error (computed from Table 2 in Bhalla \& Proffitt, 1999). The signed error function suggests that the exaggerated scaling of perceived slant appears to occur primarily in the first $10^{\circ}$, This is consistent with the scale-expansion account, because this is the range of slants within which the majority of locomotor action occurs. For hills between $10^{\circ}$ and $35^{\circ}$, the signed error is fairly constant, with a mean value of $21^{\circ}$.

Although the observed signed error function for hills differs substantially from what we have documented for surfaces within reach, this difference may be mainly a function of viewing distance. Bridgeman and Hoover (2008) have shown that nearer portions of hills appear shallower than farther portions. This observation is consistent with our data: Whereas a near surface must be about $34^{\circ}$ to appear to be $45^{\circ}$, a hill, viewed at several meters distance, need be only $24^{\circ}$ to appear $45^{\circ}$. On the other hand, for both large and small surfaces, vertical and horizontal seem to remain easily recognizable.

Thus, our account of the biases we have observed depends on two distinct principles. On the one hand, the categorical orientations of horizontal and vertical tend to be accurately perceived. On the other hand, the space between these two references is distorted in a manner 
that expands the perceptual scaling of orientation from horizontal.

\section{AUTHOR NOTE}

This research was supported by Hans Wallach fellowship funds and by a Swarthmore College Faculty Research Grant. Natasha Tonge and Selmaan Chettih assisted with the collection of data. Correspondence concerning this article should be addressed to F. H. Durgin, Department of Psychology, Swarthmore College, 500 College Avenue, Swarthmore, PA 19081 (e-mail: fdurgin1@swarthmore.edu).

\section{REFERENCES}

Banks, M. S., Hooge, I. T. C., \& Backus, B. T. (2001). Perceiving slant about a horizontal axis from stereopsis. Journal of Vision, 1(2, Art. 1), 55-79. doi:10.1167/1.2.1

BanKs, W. P., \& Coleman, M. J. (1981). Two subjective scales of number. Perception \& Psychophysics, 29, 95-105.

Bhalla, M., \& Proffitt, R. D. (1999). Visual-motor recalibration in geographical slant perception. Journal of Experimental Psychology: Human Perception \& Performance, 25, 1076-1096.

Bridgeman, B., \& Hoover, M. (2008). Processing spatial layout by perception and sensorimotor interaction. Quarterly Journal of Experimental Psychology, 61, 851-859.

Clark, W. C., Smith, A. H., \& Rabe, A. (1956). The interaction of surface texture, outline gradient, and ground in the perception of slant. Canadian Journal of Psychology, 10, 1-8.

Creem, S. H., \& Proffitt, D. R. (1998). Two memories for geographical slant: Separation and interdependence of action and awareness. Psychonomic Bulletin \& Review, 5, 22-36.

Dick, M., \& Hochstein, S. (1989). Visual orientation estimation. Perception \& Psychophysics, 46, 227-234.

Dunham, D. W., \& SchöNe, H. (1984). Substrate slope and orientation in land hermit crab, Coenobita clypetus (Decapoda, Coenobitidae). Journal of Comparative Physiology A, 154, 511-513.

Durgin, F. H. (2009). When walking makes perception better. Current Directions in Psychological Science, 18, 43-47.

Durgin, F. H., Baird, J. A., Greenburg, M., Russell, R., ShaughNESSY, K., \& WaYmouth, S. (2009). Who is being deceived? The experimental demands of wearing a backpack. Psychonomic Bulletin \& Review, 16, 964-969.

Durgin, F. H., Fox, L. F., \& Kim, D. H. (2003). Not letting the left leg know what the right leg is doing: Limb-specific locomotor adaptation to sensory-cue conflict. Psychological Science, 16, 567-572.

Durgin, F. H., Hajnal, A., Li, Z., Tonge, N., \& Stigliani, A. (2010). Palm boards are not action measures: An alternative to the twosystems theory of geographical slant perception. Acta Psychologica, 134, 182-197.

Eby, D. W., \& Braunstein, M. L. (1995). The perceptual flattening of three-dimensional scenes enclosed by a frame. Perception, 24, 981993.

Engebretson, P. H., \& Huttenlocher, J. (1996). Bias in spatial location due to categorization: Comment on Tversky and Schiano. Journal of Experimental Psychology: General, 125, 96-108.

FISHER, G. H. (1968). The frameworks for perceptual localization (Tech. Rep. 70/GEN/9617). Newcastle upon Tyne, U.K.: University of Newcastle upon Tyne.

FLOCK, H. R. (1965). Optical texture and linear perspective as stimuli for slant perception. Psychological Review, 72, 505-514.

Gibson, J. J. (1950). The perception of visual surfaces. American Journal of Psychology, 63, 367-384.

Gibson, J. J., \& Cornsweet, J. (1952). The perceived slant of visual surfaces-optical and geographical. Journal of Experimental Psychology, 44, 11-15.

Gruber, H. E., \& Clark, W. C. (1956). Perception of slanted surfaces. Perceptual \& Motor Skills, 6, 97-106.

Hajnal, A., Abdul-MalaK, D. T., \& Durgin, F. H. (in press). The perceptual experience of slope by foot and by finger. Journal of Experimental Psychology: Human Perception \& Performance. doi:10.1037/a0019950

HARRIS, C. S. (1963). Adaptation to displaced vision: Visual, motor, or proprioceptive change? Science, 140, 812-813. doi:10.1126/ science. 140.3568 .812
HARRIS, C. S. (1980). Insight or out of sight? Two examples of perceptual plasticity in the human adult. In C. S. Harris (Ed.), Visual coding and adaptability (pp. 95-150). Hillsdale, NJ: Erlbaum.

Haun, D., Allen, G., \& Wedell, D. (2005). Bias in spatial memory: A categorical endorsement. Acta Psychologica, 188, 149-170.

Howard, I. P., \& KaneKo, H. (1994). Relative shear disparities and the perception of surface inclination. Vision Research, 34, 2505-2517.

Howe, C., \& Purves, D. (2004). Natural-scene geometry predicts the perception of angles and line orientation. Proceedings of the National Academy of Sciences, 102, 1228-1233.

Huttenlocher, J., Hedges, L., \& Duncan, S. (1991). Categories and particulars: Prototype effects in estimating spatial location. Psychological Review, 98, 352-376.

KAMmANN, R. (1967). The overestimation of vertical distance and slope and its role in the moon illusion. Perception \& Psychophysics, 2, 585589.

KANEKO, H., \& HowARD, I. P. (1997). Spatial properties of shear disparity processing. Vision Research, 37, 315-323.

KNILL, D. C. (1998). Discrimination of planar slant from texture: Human and ideal observers compared. Vision Research, 38, 1683-1711.

KNILl, D. C., \& SAUNDERS, J. A. (2003). Do humans optimally integrate stereo and texture information for judgments of surface slant? Vision Research, 43, 2539-2558.

Li, Z., \& Durgin, F. H. (2009). Downhill slopes look shallower from the edge. Journal of Vision, 9(11, Art. 6), 1-15. doi:10.1167/9.11.6

NARDI, D., \& Bingham, V. P. (2009). Pigeon (Columba livia) encoding of a goal location: The relative importance of shape geometry and slope information. Journal of Comparative Psychology, 123, 204-216.

Norman, J. F., Crabtree, C. E., Bartholomew, A. N., \& Ferrell, E. L. (2009). Aging and the perception of slant from optical texture, motion parallax, and binocular disparity. Attention, Perception, \& Psychophysics, 71, 116-130.

OoI, T. L., Wu, B., \& HE, Z. J. (2006). Perceptual space in the dark affected by the intrinsic bias of the visual system. Perception, 35, 605-624.

O'Shea, R. P., \& Ross, H. E. (2007). Judgments of visually perceived eye level (VPEL) in outdoor scenes: Effects of slope and height. Perception, 36, 1168-1178.

Perrone, J. A. (1982). Visual slant underestimation: A general model. Perception, 11, 641-654.

ProffitT, D. R. (2006). Embodied perception and the economy of action. Perspectives on Psychological Science, 1, 110-122.

Proffitt, D. R., Bhalla, M., Gossweiler, R., \& Midgett, J. (1995). Perceiving geographical slant. Psychonomic Bulletin \& Review, 2, 409-428.

Redding, G. M., \& Wallace, B. (1988). Components of prism adaptation in terminal and concurrent exposure: Organization of the eye-hand coordination loop. Perception \& Psychophysics, 44, 59-68.

Ross, H. E. (1974). Behaviour and perception in strange environments. London: Allen \& Unwin.

SEDGWICK, H. A. (1986). Space perception. In K. R. Boff, L. Kaufman, \& J. P. Thomas (Eds.), Handbook of perception and human performance (pp. 21.1-21.57). New York: Wiley.

Simmering, V. R., Spencer, J. P., \& SCHÖNER, G. (2006). Referencerelated inhibition produces enhanced position discrimination and fast repulsion near axes of symmetry. Perception \& Psychophysics, 68, 1027-1046.

Spencer, J. P., Simmering, V. R., \& Schutte, A. R. (2006). Toward a formal theory of flexible spatial behavior: Geometric category biases generalize across pointing and verbal response types. Journal of Experimental Psychology: Human Perception \& Performance, 32, 473-490.

TodD, J., GuCKEs, K., \& Egan, E. (2009). The perception of surface slant from monocular texture gradients and binocular disparity [Abstract]. Journal of Vision, 9(8), 53a. doi:10.1167/9.8.53

TVERSKy, B., \& Schiano, D. (1989). Perceptual and conceptual factors in distortions in memory for maps and graphs. Journal of Experimental Psychology: General, 118, 387-398.

Wolfe, J. M., Friedman-Hill, S. R., Stewart, M. I., \& O'Connell, K. M. (1992). The role of categorization in visual search for orientation. Journal of Experimental Psychology: Human Perception \& Performance, 18, 34-49.

(Manuscript received March 10, 2010; revision accepted for publication April 30, 2010.) 